\title{
Performance prediction of a mixed flow turbine
}

\author{
Miloud Abidat ${ }^{\mathrm{a}}$, Mohammed Kamel Hamidou, Madjid Hachemi, Mohammed Hamel \\ AND Sid Ali Litim \\ Laboratoire de Mécanique Appliquée, Faculté de Génie Mécanique, Université des Sciences et de la Technologie d'Oran, \\ BP 1505, Oran El M'Naouer, 31000 Oran, Algeria
}

Received 4 September 2006, Accepted 17 October 2007

\begin{abstract}
Turbochargers are widely used in Diesel engines as a means of increasing the output power. Most of them are fitted with radial or mixed flow turbines. In applications where high boost pressure is required, radial turbines are replaced with mixed flow turbines with positive rotor inlet blade angle so that they can achieve a maximum efficiency at a lower value of blade speed to isentropic expansion velocity ratio than the usual 0.7 (for radial turbines). This study, performed with the ICEM and CFX softwares of ANSYS, presents a numerical performance prediction of a mixed flow turbine for a wide range of rotational speeds and pressure ratios. The influence of the clearance between the rotor tip blades and the casing on the turbine performances is also investigated. A simulation of the turbine under pulsed inlet flow conditions is also presented.
\end{abstract}

Key words: Mixed flow turbine / performance / turbocharger / finite volume method / efficiency / pulsating flow

\begin{abstract}
Résumé - Prédiction des performances d'une turbine semi-axiale. Les turbocompresseurs de suralimentation sont largement utilisés dans les moteurs Diesel pour augmenter la puissance. La plupart sont équipés de turbines radiales ou semi-axiales. Dans les applications où une bouffée à haute pression est exigée, les turbines radiales sont remplacées par les turbines semi-axiales. Ces dernières se caractérisent par un angle d'aube positif à l'entrée du rotor afin d'obtenir un rendement maximal pour un rapport de vitesses (rapport de la vitesse périphérique du rotor à la vitesse d'expansion isentropique) inférieur à la valeur habituelle 0,7 pour les turbines radiales. Cette étude, réalisée à l'aide des logiciels ICEM et CFX d'ANSYS, présente une prédiction numérique des performances d'une turbine semi-axiale pour une grande gamme de vitesses de rotation et de taux de détente. L'influence du jeu entre les aubes du rotor et le carter sur les performances de la turbine est aussi étudiée. Une simulation de la turbine sous des conditions d'un écoulement pulsé à l'entrée est aussi présentée.
\end{abstract}

Mots clés : Turbines semi-axiales / performance / turbocompresseur / méthode des volumes finis / rendement / écoulement pulsé

\section{Introduction}

Turbochargers are widely used in Diesel engines as a means of increasing the output power. They were used principally in the marine propulsion field at their early apparition and became in recent years commonly used for road transport applications.

Turbochargers with radial compressors and radial turbines are the most commonly used because of their ability to deliver/absorb more power in comparison to axial ones of similar size. Radial turbines are mainly used for automotive engines applications and have the advantage of

\footnotetext{
${ }^{a}$ Corresponding author: miloud_abidat04@yahoo.fr
}

retaining a high efficiency when reduced to small sizes. They can operate at high expansion ratio on one single stage. On the other hand, axial turbines, which are used for large turbocharger (marine and railway applications) engines, are generally made of several stages.

The turbine which is an important component of a turbocharger consists essentially of a casing or volute, a rotor and a diffuser. The casing, whose function is to convert a part of the engine exhaust gas energy into kinetic energy and direct the flow towards the rotor inlet at an appropriate flow angle, can be vaneless or fitted with a nozzle guided vane. In the second case, the turbine has a good aerodynamic performance at design conditions but 


\section{Nomenclature}

\begin{tabular}{|c|c|c|c|}
\hline$b$ & Rotor inlet blade height & $u$ & Fluctuating velocity vector \\
\hline$e$ & Clearance between the rotor and the casing & $\omega$ & Turbulent frequency \\
\hline$H$ & Total enthalpy & & \\
\hline$h$ & Enthalpy fluctuation & & \\
\hline$h_{\mathrm{S}}$ & Static enthalpy & & \\
\hline$k$ & Turbulent kinetic energy & $\varepsilon$ & Turbulent kinetic energy dissipation \\
\hline$P$ & Static pressure & $\mu_{\mathrm{t}}$ & Turbulent viscosity \\
\hline$q_{\mathrm{m}}$ & Mass flow rate & $\tau$ & Molecular stress tensor \\
\hline$q_{\mathrm{mr}}$ & Reduced mass flow rate & $\rho$ & Density \\
\hline$T$ & Static temperature, pulse period & & Subscripts \\
\hline$t$ & Time & $0^{*}$ & Turbine inlet stagnation condition \\
\hline
\end{tabular}

a poor efficiency at off design conditions compared with a vaneless stator.

Radial turbines have been adopted for small engine applications because of their simplicity, low cost, reliability and relatively high efficiency. The turbine requirements in highly loaded turbocharger engines are changing: higher air/fuel ratio required for emissions and the use of intercoolers result in significantly lower exhaust temperatures. This together with the fact that more power required for boost pressure has to be taken from the exhaust has resulted in smaller turbine housings being used, which reduces the turbine efficiency. The turbine speed is limited by stress, so that the requirement is for a turbine stage with maximum efficiency at a lower value of blade speed to isentropic expansion velocity ratio than the usual 0.7 (for radial turbines). The most feasible way to do this is to make the inlet blade angle positive as opposed to the usual value of zero for radial turbines with radial blade fibres. This means that the rotor inlet can not be radial but mixed, so that inlet streamlines in the meridional plane have both radial and axial components. It is the only possible way to have non zero inlet rotor blade angle while retaining radial blade fibres. The projection of the mean blade surface on a reference cylinder is represented by a unique curve or camber line. This type of blade geometry with radially directed fibres, used for mixed flow rotors, has the advantage of avoiding additional stresses due to blending.

Three mixed flow turbines, with rotor $\mathrm{A}, \mathrm{B}$ and $\mathrm{C}$, have been designed to meet these constrains and then tested at Imperial College by Abidat [1] and Abidat et al. [2]. The two rotors $\mathrm{A}$ and $\mathrm{C}$ have a 20 degrees constant rotor inlet blade angle and differ only by the number of blades: rotor A has 12 blades while turbine $\mathrm{C}$ has only 10. Rotor B was designed for a constant incidence angle at design conditions. It has the same number of blades and the same exducer geometry as rotor A but shorter axial length. The turbine was designed to match the following design conditions (Tab. 1).

This turbine (referred to as turbine A) has been used by Abidat et al. [3], Arcoumanis et al. [4] and Chen et al. [5] for steady and unsteady flow performance analyses. Turbine B on the other hand has been investigated under steady and pulsating flow conditions by Karamanis et al. [6]. Although, a relatively abundant literature on
Table 1. Design conditions.

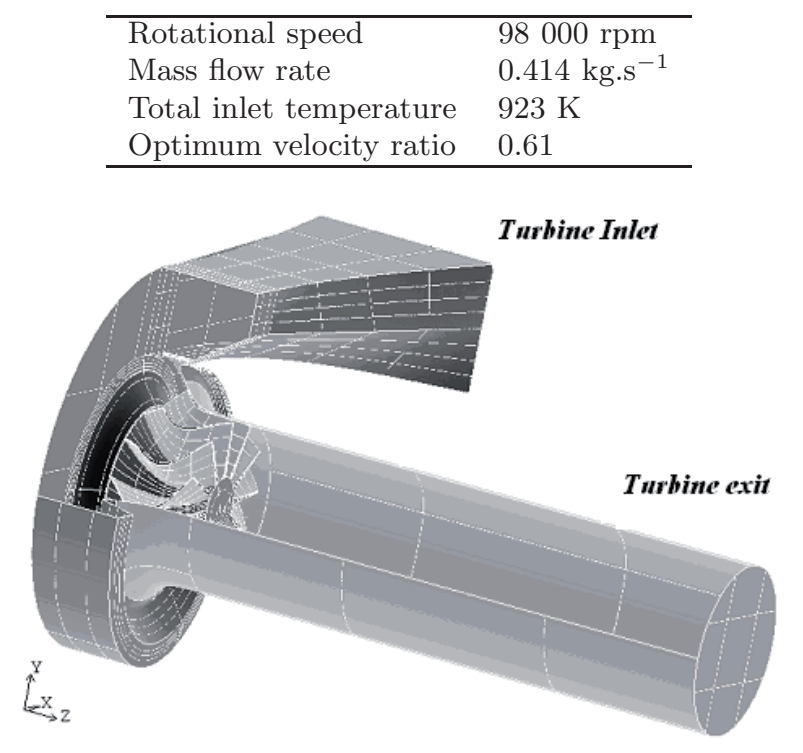

Fig. 1. Mixed flow turbine.

the performance of radial turbines (Bhinder \& Gulati [7], Gabette et al. [8], Dale \& Watson [9], Chen \& Winterbone [10] and Hammoud et al. [11]) is available, more work on mixed flow turbines needs to be done.

This study presents a numerical performance prediction of the mixed flow turbine A for a wide range of rotational speeds and pressure ratios. The influence of the clearance between the rotor tip blades and the casing on the turbine performances will also be investigated. In addition, transient performance prediction is undertaken.

The ICEM tool is used to build the full turbine geometry and to generate the mesh while the computational tests are performed with the CFX software.

\section{Flow simulation in a mixed flow turbine}

\subsection{Turbulent flow model}

The highly three dimensional flow in the mixed flow turbine shown in Figure 1 is obtained by solving numerically the Reynolds averaged equations of mass, 
momentum and energy conservation for compressible flow. Bradshaw et al. [12] stated that the density fluctuations for a compressible fluid do not affect the flow in a meaning way. When the fluctuations speed are about $5 \%$ of mean velocity, the density fluctuations are negligible until Mach numbers of about 3 to 5 .

- Mass conservation equation :

$$
\frac{\partial \rho}{\partial t}+\nabla \cdot(\rho \boldsymbol{U})=0
$$

where $\rho$ is the density and $\boldsymbol{U}$ the mean velocity vector.

- Momentum conservation equations:

$$
\frac{\partial(\rho \boldsymbol{U})}{\partial \mathrm{t}}+\nabla \cdot(\rho \boldsymbol{U} \otimes \boldsymbol{U})=\nabla(-p \delta+\tau-\rho \overline{\boldsymbol{u} \otimes \boldsymbol{u}})+S_{\mathrm{M}}
$$

where $\boldsymbol{u}, p, \delta, \tau, \rho \overline{\boldsymbol{u} \otimes \boldsymbol{u}}$ and $S_{\mathrm{M}}$ are the fluctuating velocity vector, the pressure, Kronecker delta function, the molecular stress tensor, the Reynolds stress tensor and a source term respectively. The Coriolis and centrifugal forces are included in the source term.

- Energy conservation equation:

$$
\frac{\partial(\rho H)}{\partial t}+\nabla \cdot(\rho \boldsymbol{U}-\rho \overline{\boldsymbol{u} h}-\lambda \nabla T)=\frac{\partial p}{\partial t}
$$

In this equation, $H$ is the mean total enthalpy given by

$$
H=h_{\mathrm{S}}+\frac{1}{2} \boldsymbol{U}^{2}+k
$$

and where $h_{\mathrm{S}}$ is the mean static enthalpy, $\lambda$ is the thermal conductivity, $T$ is the mean static temperature and $p$ is the static pressure. The additional term $k$ in the total energy equation is the turbulent kinetic energy defined as follows:

$$
k=\frac{1}{2} \boldsymbol{u}^{2}
$$

Static temperature $T$, static pressure $p$ and density $\rho$ are related by the equation of state: $p=\rho R T$, where $R$ is the air gaz constant.

The turbulence is modeled by the standard $k-\varepsilon$ equation. This model is based on eddy viscosity concept which assumes that the Reynolds stresses $-\rho \overline{u_{i} u_{j}}$ can be expressed in terms of the mean velocity gradients and the eddy or turbulent viscosity $\mu_{\mathrm{t}}$ in a manner analogous to the viscous stresses $\tau_{i j}$ for laminar Newtonian flows.

$$
\begin{aligned}
\tau_{i j} & =\mu\left(\frac{\partial U_{j}}{\partial x_{i}}+\frac{\partial U_{i}}{\partial x_{j}}\right)-\frac{2}{3} \mu \delta_{i j} \frac{\partial U_{k}}{\partial x_{k}} \\
-\rho \overline{u_{i} u_{j}} & =\mu_{\mathrm{t}}\left(\frac{\partial U_{j}}{\partial x_{i}}+\frac{\partial U_{i}}{\partial x_{j}}\right)-\frac{2}{3} \mu_{\mathrm{t}} \delta_{i j} \frac{\partial U_{k}}{\partial x_{k}}-\frac{2}{3} \delta_{i j} \rho k
\end{aligned}
$$

This model assumes that the eddy viscosity $\mu_{\mathrm{t}}$ is linked to the turbulent kinetic energy $k$ and its dissipation $\varepsilon$ through the following relation:

$$
\mu_{\mathrm{t}}=\rho C_{\mu} \frac{k^{2}}{\varepsilon}
$$

Table 2. Turbine geometry.

\begin{tabular}{ll}
\hline Volute inlet area & $2.12 \times 10^{-3} \mathrm{~m}^{2}$ \\
Volute inlet radius & $82.50 \times 10^{-3} \mathrm{~m}$ \\
Rotor inlet mean diameter & $83.58 \times 10^{-3} \mathrm{~m}$ \\
Rotor inlet blade height & $17.99 \times 10^{-3} \mathrm{~m}$ \\
Rotor inlet blade angle & $20.0 \mathrm{deg}$ \\
Rotor inlet cone angle & $40.0 \mathrm{deg}$ \\
Exducer hub diameter & $27.07 \times 10^{-3} \mathrm{~m}$ \\
Exducer shroud diameter & $78.65 \times 10^{-3} \mathrm{~m}$ \\
Rotor exit mean blade angle & $-52.0 \mathrm{deg}$ \\
Rotor axial length & $40.00 \times 10^{-3} \mathrm{~m}$ \\
Number of blades & 12 \\
Radial and axial tip clearance & $40.00 \times 10^{-3} \mathrm{~m}$ \\
\hline
\end{tabular}

where $C_{\mu}=0.09$ and $k$ and $\varepsilon$ are defined through the following two equations

$$
\begin{aligned}
& \frac{\partial(\rho k)}{\partial t}+\nabla \cdot(\rho k \boldsymbol{U})=\nabla \cdot\left[\left(\mu+\frac{\mu_{\mathrm{t}}}{\sigma_{k}}\right) \nabla k\right]+P_{k}-\rho \varepsilon \\
& \frac{\partial(\rho \varepsilon)}{\partial t}+\nabla \cdot(\rho \varepsilon \boldsymbol{U})=\nabla \cdot\left[\left(\mu+\frac{\mu_{\mathrm{t}}}{\sigma_{\varepsilon}}\right) \nabla \varepsilon\right]+\frac{\varepsilon}{k}\left(C_{1 \varepsilon} P_{k}-C_{2 \varepsilon} \rho \varepsilon\right)
\end{aligned}
$$

where $P_{k}$ is the turbulence production and $\sigma_{\kappa}=1.00$, $\sigma_{\varepsilon}=1.30, C_{1 \varepsilon}=1.44, C_{2 \varepsilon}=1.92$ are constants determined experimentally from a wide range of turbulent flows (Patankar \& Spalding [13]).

It is worth mentioning that the $k-\varepsilon$ model like other two-equation models, which are suitable for many flows of engineering interest, become limited in applications such as:

- Flows with boundary layer separation,

- Flows with sudden changes in the mean strain rate,

- Flows in rotating fluids,

- Flows over curved surfaces.

At the expense of more resources, a Reynolds stress model or the shear stress transport (SST) $k-\omega$ model of Menter [14] will be more appropriate for complex flows such as those encountered in a turbomachine.

\subsection{Mesh generation}

The flow solution in the mixed flow turbine, shown in Figure 1, is obtained by a numerical finite volume method. The flow domain is discretised into finite volumes of tetrahedral elements. The ICEM CFD 4.CFX software is used to build the turbine geometry and to generate the unstructured mesh. The main geometrical characteristics of the mixed flow turbine are given in Table 2 .

- The influence of the rotational speed on turbine performance is performed on a complete turbine stage as shown in Figure 1. The turbine geometry is split into a stationary volute part (31512 nodes and 96883 elements) and a rotating rotor part (227930 nodes and 769279 elements). This geometry is also used to simulate the turbine performance under pulsating inlet flow conditions. 


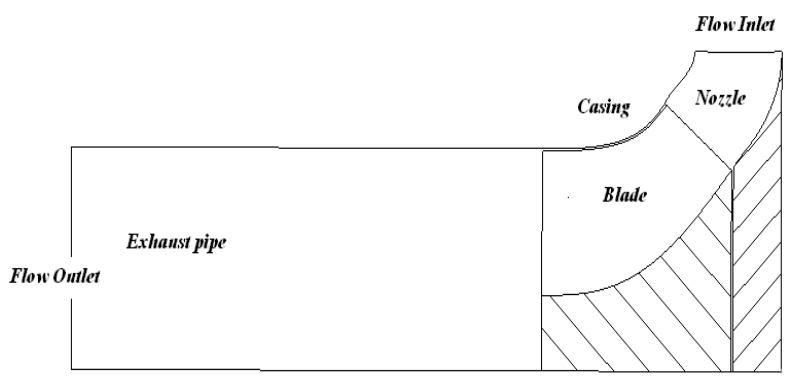

Fig. 2. Mixed flow rotor channel.

- The effect of the clearance on the turbine performance is made through a one blade to blade channel (33170 nodes and 125545 elements) as shown in Figure 2 and assuming a periodic flow on the other channels.

During the mesh generation process, care has to be taken in the choice of the first grid spacing near wall boundaries to obtain a proper resolution of the boundary layer. As a result of the use of the wall function approach to model the flow near the wall in the $k-\varepsilon$ turbulence model, it is advised that the $Y$ plus value for the near wall node has to be in the range of 20 to 100 .

\subsection{Numerical method}

The integration on the finite volumes of the equations describing the turbulent flow results in a set of discrete equations. The terms of the differential equations on the volume interfaces are obtained by a first order upwind scheme or a high resolution or second order scheme. The first order upwind scheme is used to obtain an approximate solution of the flow while the high resolution scheme is used to obtain the final solution. The pressure-velocity coupling is achieved using a coupled solver - which solves the hydrodynamic equations (for $u, v, w, p$ ) as a single system - in conjunction with a momentum-interpolation technique similar to that of Rhie \& Chow [15] to prevent pressure-field oscillations as a result of the non staggered, collocated grid arrangement.

At the turbine inlet, the flow is assumed subsonic, and therefore the total pressure and the total temperature in the stationary frame of reference as well as the flow direction are imposed. At the turbine outlet, where the flow is considered to be subsonic, the static pressure is imposed. On the solid boundaries, a no slip condition is used.

\section{Results and discussion}

The numerical method described in this paper has been used to simulate the effect of the rotor rotational speed, the rotor tip clearance, and the turbine inlet steady and pulsed flow conditions, on the performance of a mixed flow turbine. The computed tests are summarised in Table 3.
Table 3. Computed tests conditions.

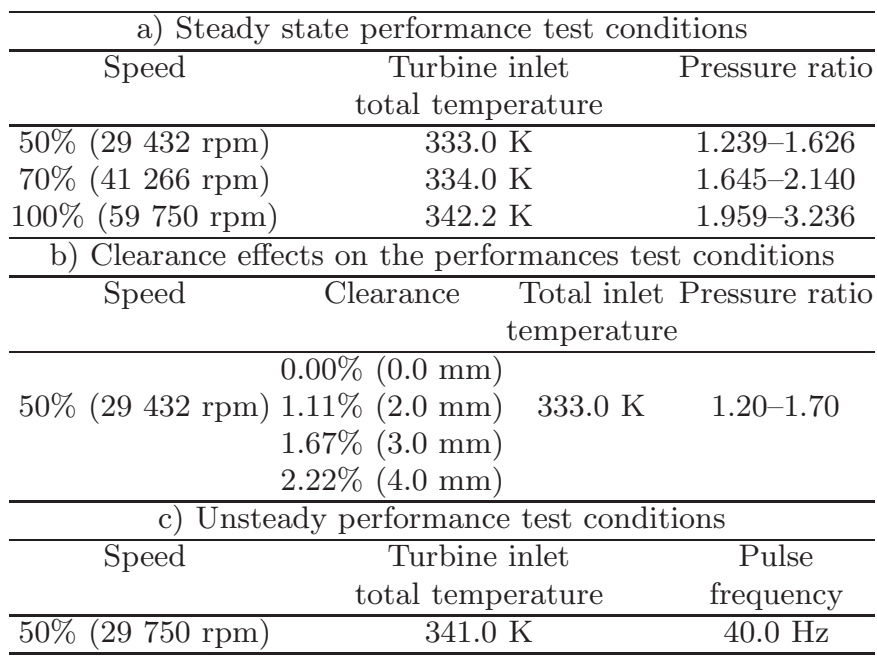

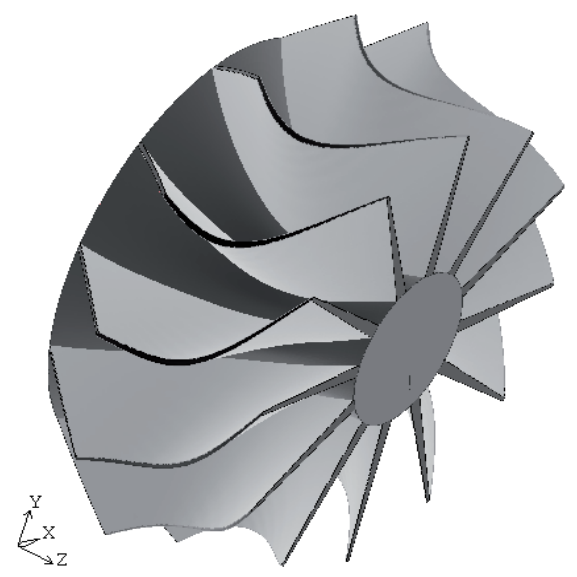

Fig. 3. Mixed flow rotor.

\subsection{Steady state performance characteristics}

The frozen rotor interface model implemented in CFX [16] is used to compute the performances of the turbine shown in Figure 1 at three rotational speeds corresponding to 50,70 and 100 per cent of the equivalent design rotational speed. The results showing the influence of the rotational speed on the performance of the mixed flow turbine are presented in Figure 4. Figure 4a shows the computed mass flow rate characteristics in terms of pressure ratio versus the reduced mass flow rate defined as:

$$
q_{\mathrm{mr}}=10^{5} q_{\mathrm{m}} \sqrt{T_{0^{*}}} / P_{0^{*}}
$$

Figure $4 \mathrm{~b}$ shows the turbine total to static efficiency versus the velocity ratio (ratio of the rotor mean peripheral velocity and the isentropic velocity obtained by an expansion from the turbine inlet stagnation condition to the turbine outlet static pressure). The computed totalto-static efficiency characteristics compare quite well with the experimental data obtained in a turbo compressor test rig by Abidat et al. [2]. The efficiency characteristics show clearly that the mixed flow turbine maximum efficiency 


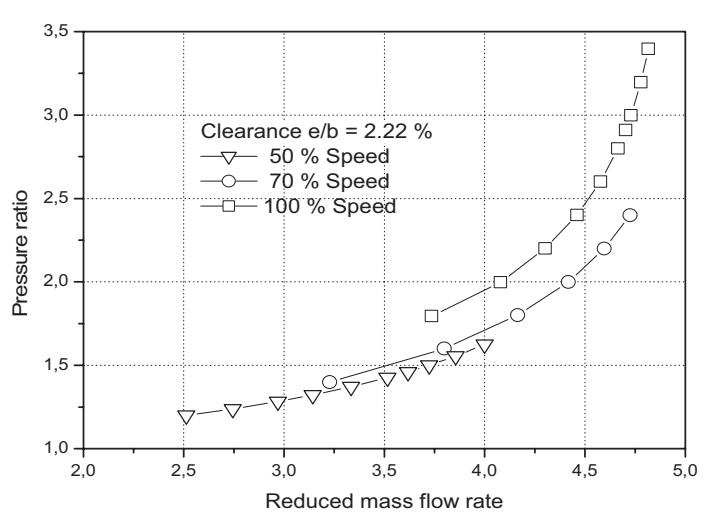

(a) Pressure ratio vs. reduced mass flow rate.

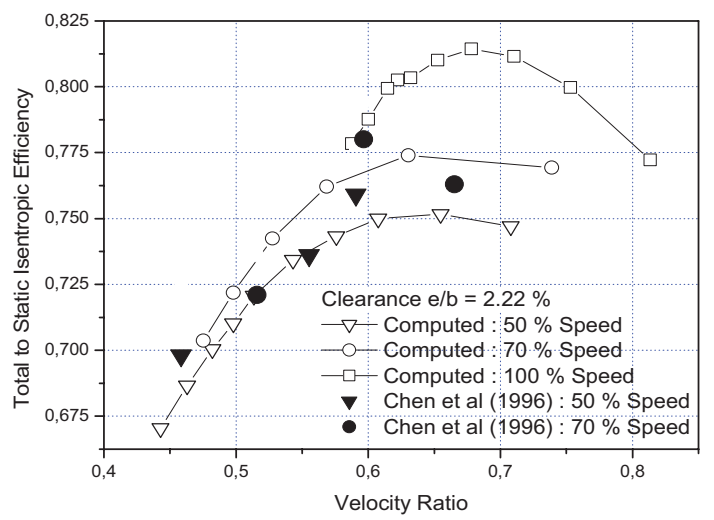

(b) Total to static efficiency vs. velocity ratio.

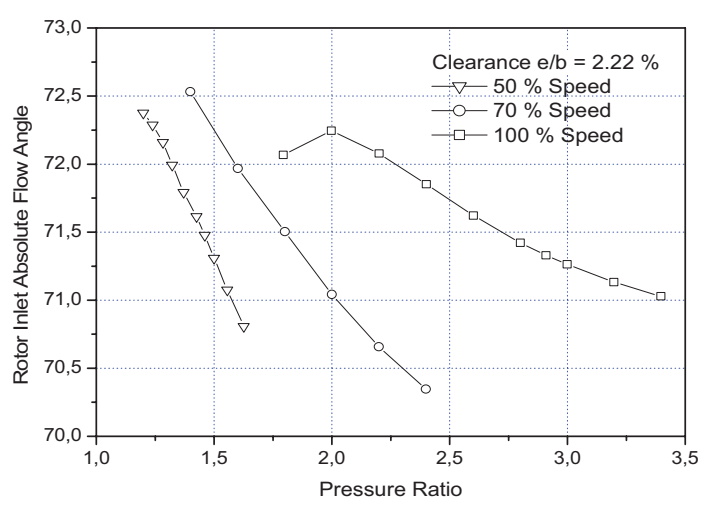

(c) Rotor inlet absolute flow angle.

Fig. 4. Effect of rotational speed on a mixed flow turbine (clearance $e / b=2.22 \%$ ).

at each rotational speed occurs at a low velocity ratio by comparison with the usual value of 0.70 for a radial turbine. Both experimental and computed results show that the optimum velocity ratio depends on the rotational speed. An experimental study on turbine B by Karamanis et al. [6] showed a similar variation of the optimum velocity ration with respect to the rotational speed. This variation can be partly explained by the fact that the absolute flow angle (angle between the absolute tangential velocity component and the meridional velocity component) at rotor inlet, as shown in Figure 4c, is not constant but varies slightly (between 70.5 and 72.5 degrees) with both the rotational speed and the turbine inlet flow conditions.

\subsection{Influence of the tip clearance on the turbine performances}

As a result of the manufacturing difficulty and the differential thermal expansion between the rotor blades and the casing, a minimal clearance between the two components is necessary. According to Rodgers [17], a minimal clearance of $0.4 \mathrm{~mm}$ for small gas turbines is required.

In order to study the effect of the tip clearance on the turbine performances, four geometries consisting of one blade to blade channel as shown in Figure 2 have been generated and meshed with the ICEM CFD 4.CFX by varying the clearance ratio $e / b(0 \%, 1.11 \%, 1.67 \%$, $2.22 \%$ ). The four tests (Tab. $3 \mathrm{~b}$ ) are performed according to the following assumptions:

- Uniform flow conditions at the domain inlet (Fig. 2). The domain inlet absolute flow has been obtained from the computation of the whole turbine (Fig. 1) and has the value of 77.0 degrees,

- Periodic flow conditions at the periodic boundary surfaces,

- Constant exit static pressure

The results presented in Figures $5 \mathrm{~b}$ and $\mathrm{c}$ show that an increase in the clearance results in a drop of the efficiency. This is due to the secondary flow resulting from the high pressure difference between the pressure side and the suction side near the blade tip in one hand and the inactive part of the flow through the section between the blade and the casing. The computed results give a $2.2 \%$ efficiency drop for the $2.22 \%$ (0.4 mm) tip clearance. With the same clearance, a $1.75 \%$ drop in efficiency is obtained by the correlation of Rohlik [18].

\subsection{Flow field at design condition}

As a result of the non symmetrical geometry of the volute and the presence of the tongue, the computation in the one blade channel does not take into account some features of the flow upstream of the rotor. Some of these flow features are illustrated by the results presented in Figures 6-8 for a whole turbine stage at an equivalent design conditions corresponding to a total temperature $T_{0^{*}}=342.2 \mathrm{~K}$ and a total pressure $P_{0^{*}}=2.91 \mathrm{bar}$ at the turbine inlet and a rotational speed of $59750 \mathrm{rpm}$. The non uniform flow at the volute outlet influences the flow inside the rotor blade channels. Figures 6 show clearly that the contours of the absolute flow angle at rotor inlet and outlet are non periodic. The same remark is made for the static pressure contours (Fig. 7) at the same stations. The principal reason of non periodicity is that the volute outlet flow is influenced by the tongue wake, and therefore, the flow at the rotor inlet is circumferentially non uniform. 


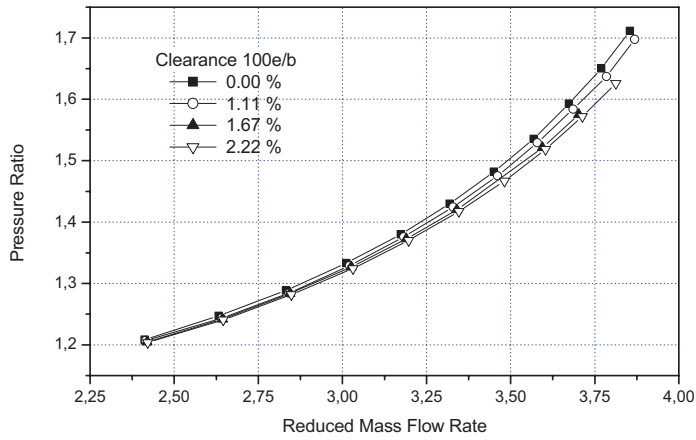

(a) Pressure ratio vs. reduced mass flow rate.

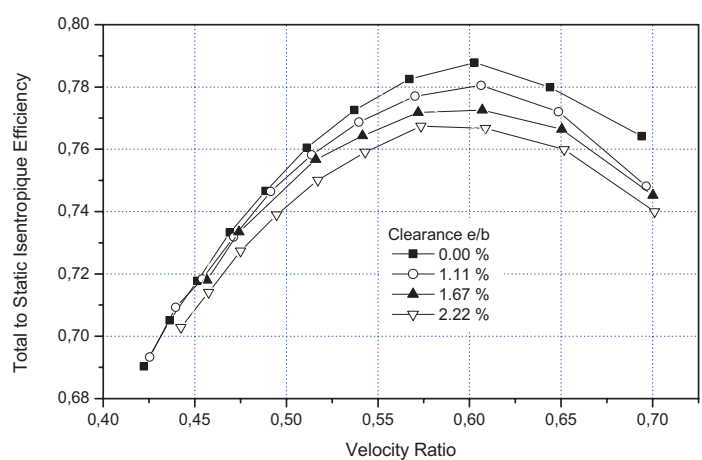

(b) Total to static efficiency vs. velocity ratio.

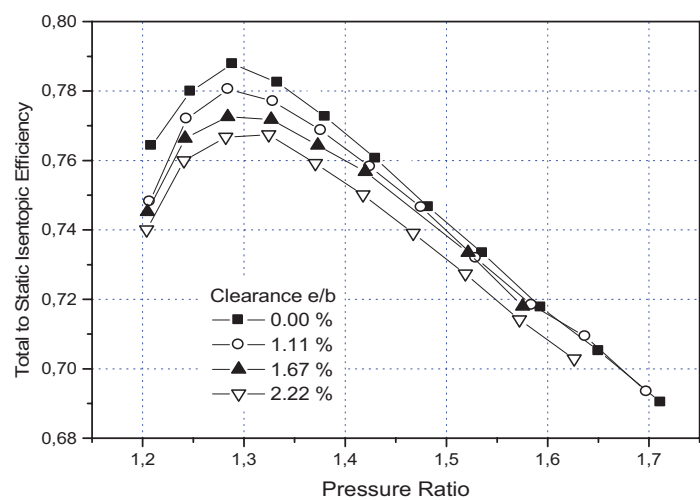

(c) Total to static efficiency vs. pressure ratio.

Fig. 5. Effect of clearance on the mixed flow turbine at $50 \%$ rotational speed.

The blade loading is illustrated in Figure 8 by the static pressure contours at one blade pressure and suction sides. The blade geometry generates the pressure gradient between the suction and pressure sides. As a result, the flow velocities on the suction side are higher than the velocities on the pressure side.

The positive flow deviations from the blade trailing edge observed in Figure 6 imply a possible flow separation from the suction side of the blades. The traverse results in Figure 6 show strong positive deviations from the blades near the hub, which outline that the suction side of the hub is the critical place where flow separation is likely to occur. The sharper falling of efficiency of the mixedflow turbine at lower pressure ratios (Fig. 5) is due to the

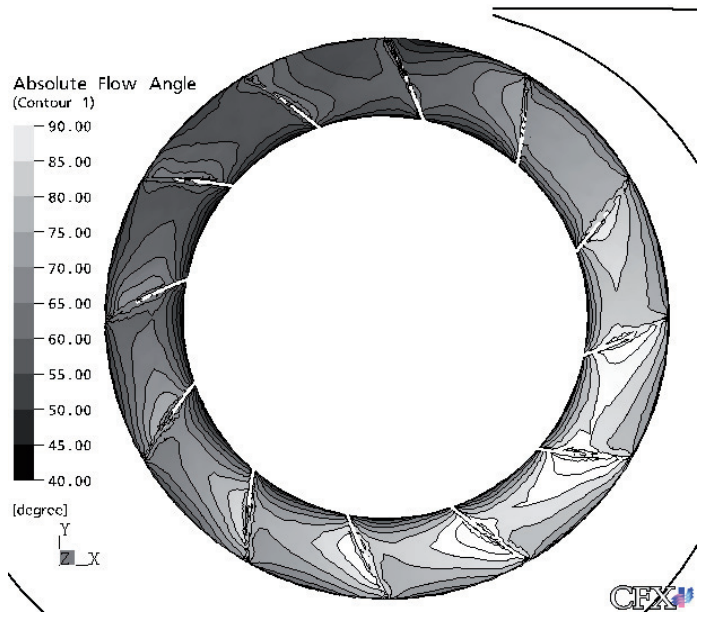

(a) Rotor inlet.

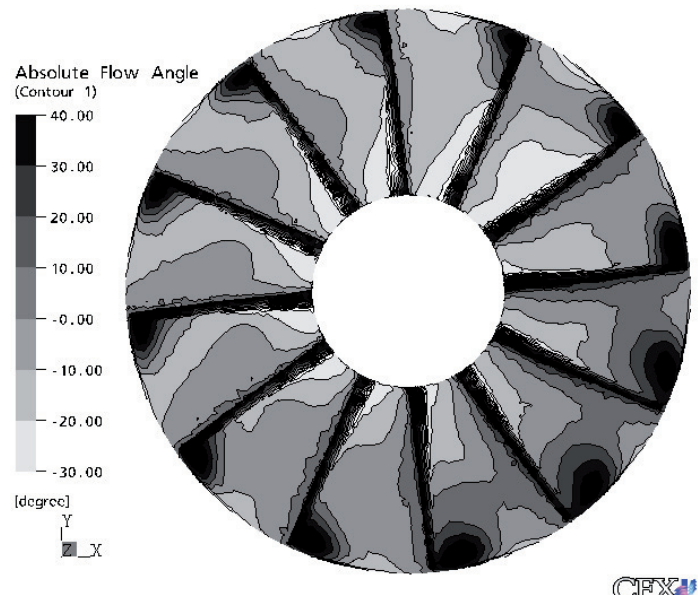

(b) Rotor outlet.

Cक्वर्य

Fig. 6. Rotor inlet and outlet absolute flow angle.

flow separation. Increasing the pressure ratio reduces the tendency to separate as indicated by Chen et al. [19].

\subsection{Unsteady performance prediction}

The volute and rotor domains were connected using the Generalized Grid Interface (GGI) implemented in CFX5. To analyze the coupled rotor-stator configuration, an interface between rotating and fixed components has to be defined. The Multiple Frames of Reference (MFR) allows the analysis of situations involving domains that are rotating relative to one another. For this part of the study, this feature focuses on the investigation of rotor/stator interaction for rotating machinery using the transient rotor/stator interface model [16].

In order to simulate the mixed flow turbine under real conditions, unsteady flow computations are performed using the Second Order Backward Euler scheme to approximate the transient term. The inlet total pressure signal with $40 \mathrm{~Hz}$ pulse frequency shown in Figure 9 is taken from the work of Chen et al. [5]. The rotational 


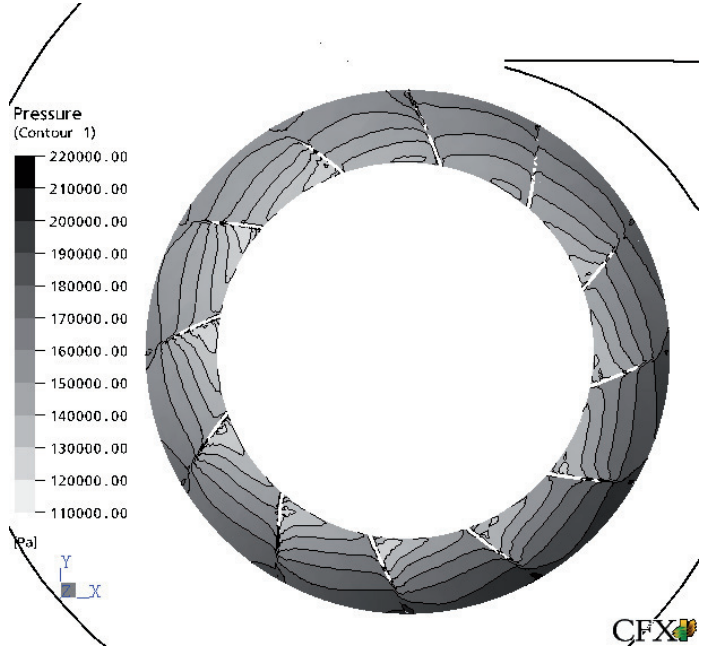

(a) Rotor inlet.

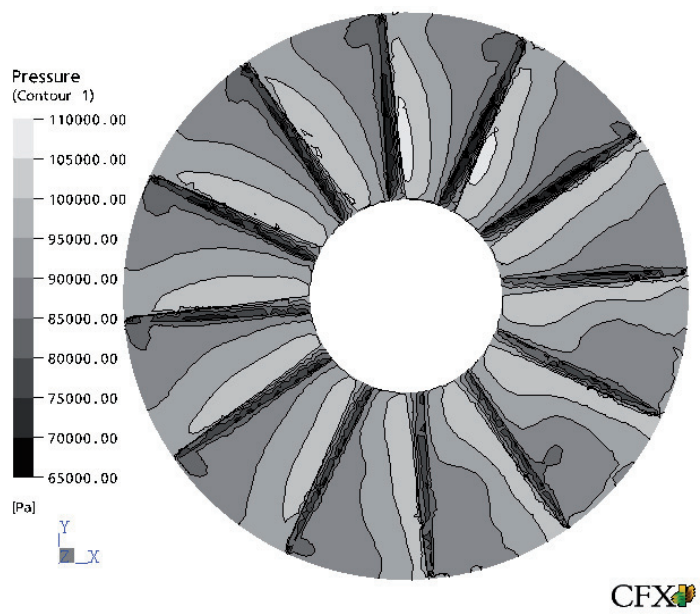

(b) Rotor outlet.

Fig. 7. Rotor inlet and outlet pressure contours.

speed $(29750 \mathrm{rpm})$ and the total turbine inlet temperature $(341.0 \mathrm{~K})$ are kept constant. The results are presented in Figures 10 to 14. The computed instantaneous turbine inlet mass flow rate, in Figure 10, compares well with those obtained by Chen et al. [5] and Abidat et al. [3] who used the same mixed flow turbine.

The differences, during one period, seen between prediction and measurement are partly due to the fact that the response of the experimental turbine is damped through the shaft connection with the compressor. In addition, there is a degree of uncertainty over the measurement of mass flux [20].

Figure 11 shows the instantaneous mass flow rate at different stations of the mixed flow turbine stage (Fig. 1), these stations correspond to the turbine inlet (volute inlet), the rotor inlet, the rotor outlet and the turbine exit (exhaust pipe) respectively. The two curves corresponding to the rotor inlet and outlet are coincident and therefore the assumption of a quasi steady rotor adopted in 1D models is justified. These two curves depart slightly

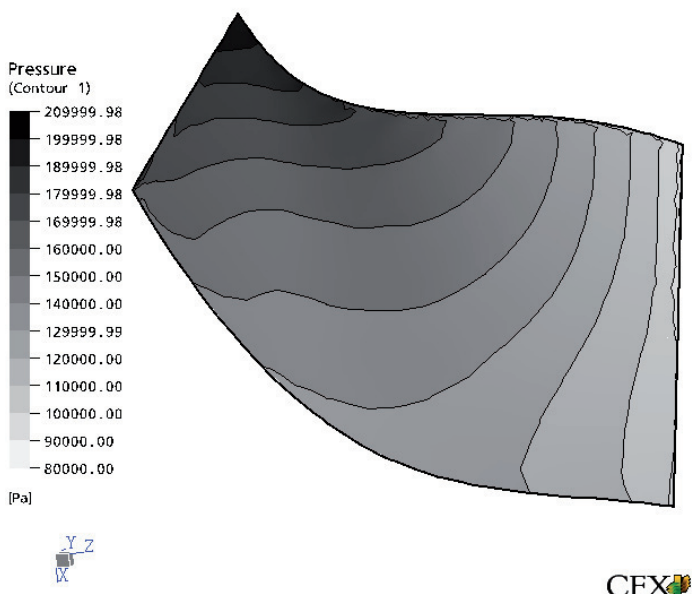

(a) Pressure side.

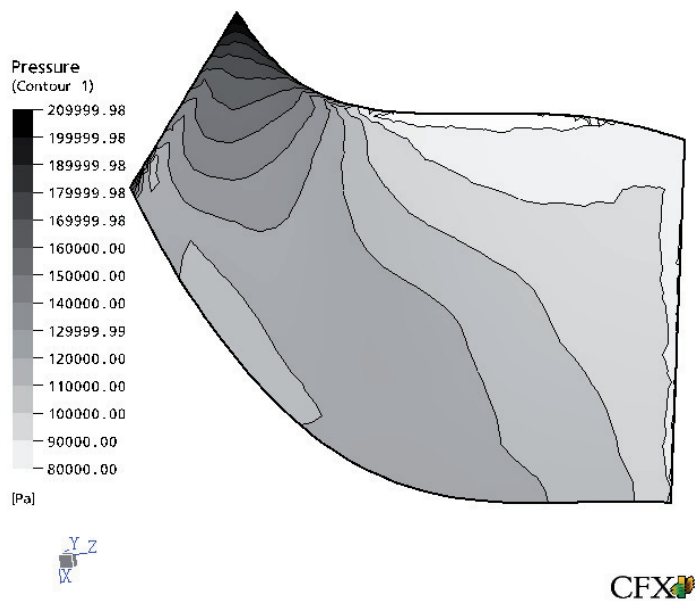

(b) Suction side.

Fig. 8. Mixed flow rotor blade pressure contours.

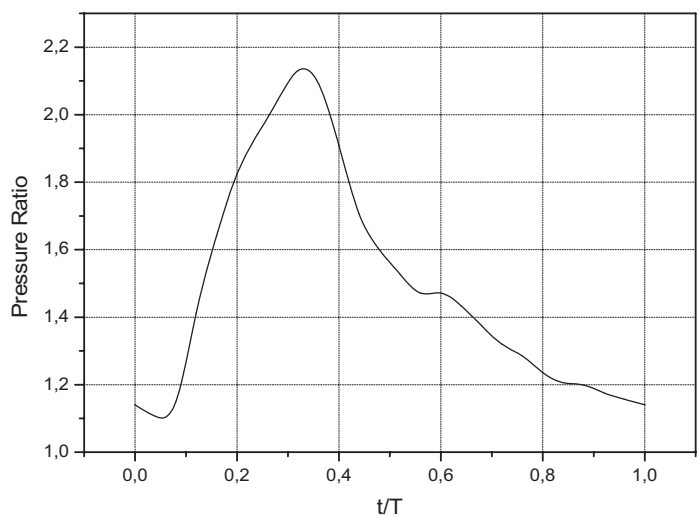

Fig. 9. Pulsating total to static pressure ratio [5].

from that at the turbine outlet. The turbine inlet instantaneous mass flow rate is however out of phase from those at the three other stations. There is a degree of time lag associated with the "filling and emptying" of the volute domain as the turbine acts as a restriction nozzle [19].

The inlet pulsating flow conditions result in turbine characteristics which depart from the quasi steady one in 


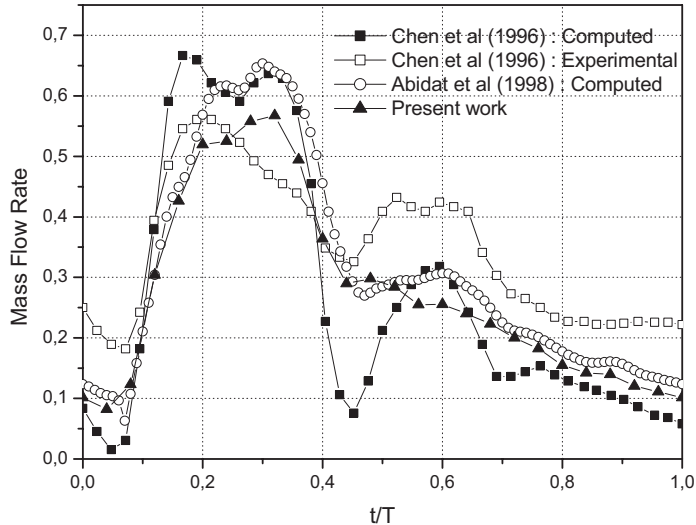

Fig. 10. Instantaneous turbine inlet mass flow rate at $50 \%$ rotational speed and $40 \mathrm{~Hz}$ pulse frequency.

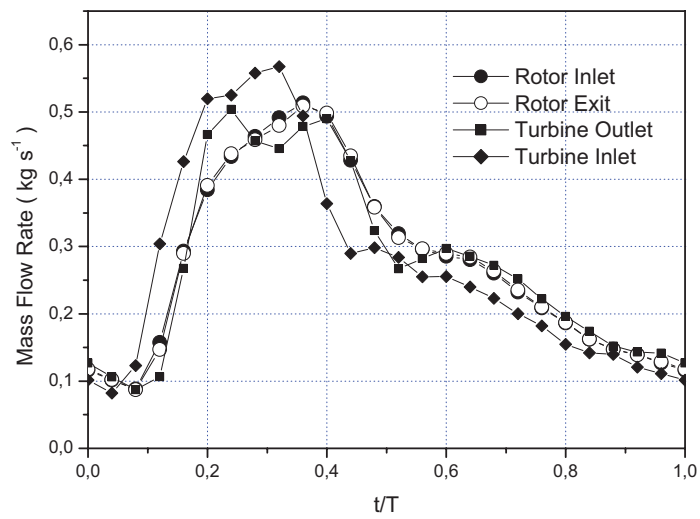

Fig. 11. Instantaneous mass flow rate at different stations of the mixed flow turbine.

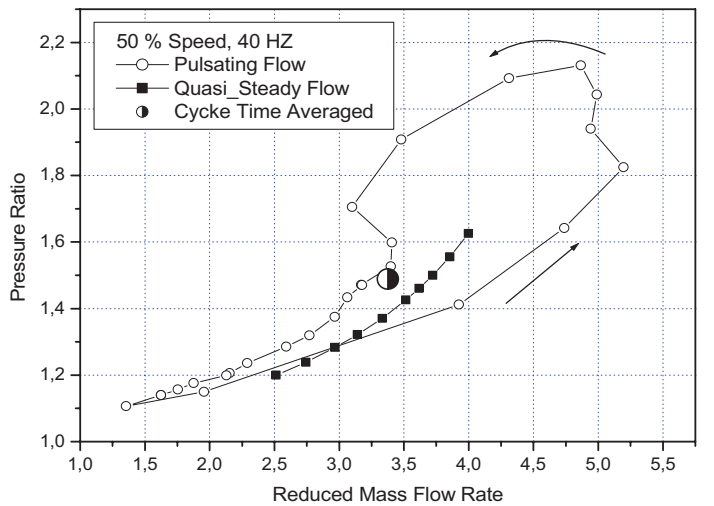

Fig. 12. Pressure ratio versus reduced mass flow rate.

a hysterisis like shape as shown in Figure 12. The cycle averaged mass flow rate does not lie in the quasi-steady state curve. Gabette et al. [8] and Abidat et al. [3] showed that the cycle averaged mass flow rate and the cycle averaged output power depend on both the pulse amplitude and the pulse frequency.

Figures 13 and 14 shows the instantaneous mean absolute and relative flow angles at rotor inlet and rotor outlet. Deviation of the absolute flow angles at rotor outlet remains relatively small during the first portion of the inlet

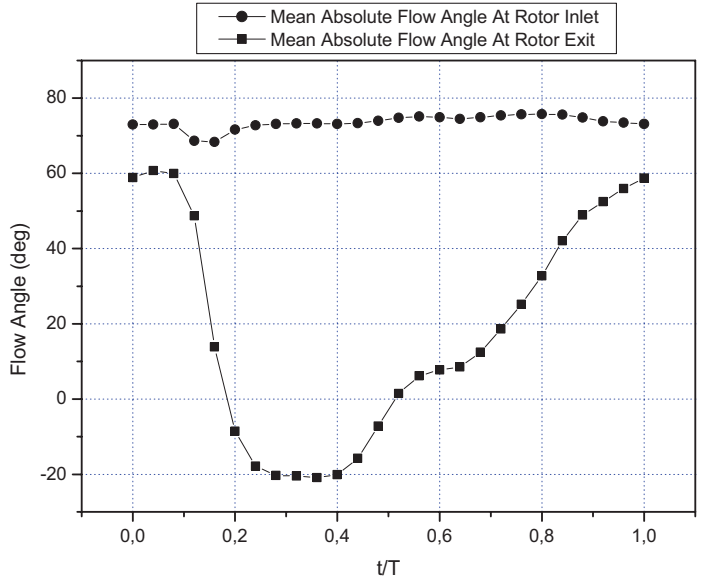

Fig. 13. Mean instantaneous absolute flow angle at rotor inlet and outlet.

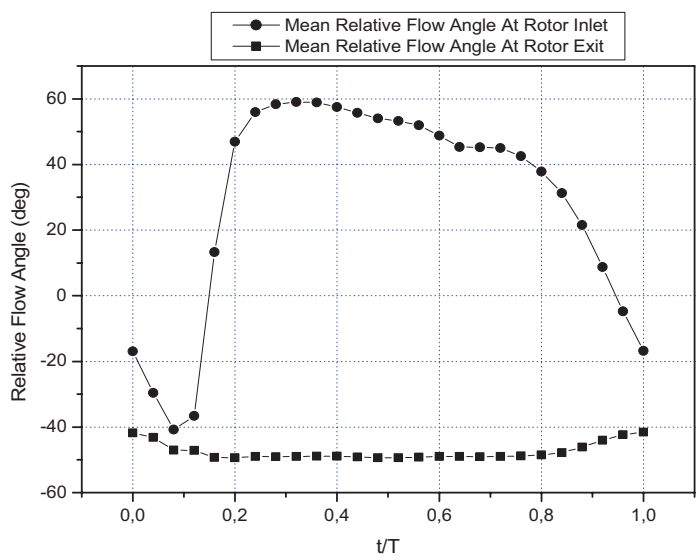

Fig. 14. Mean instantaneous relative flow angle at rotor inlet and outlet.

pulse wave, but then decreases rapidly to approximately $-20 \mathrm{deg}$, leading to poor flow guidance and consequently to low turbine efficiency.

\section{Conclusion}

This paper presents a numerical prediction of the performance of a mixed flow turbine under inlet steady and pulsed flow conditions. The ANSYS-CFX code is used to solve the highly three dimensional viscous flow in the mixed flow turbine. The computed steady state total to static efficiency is in reasonable agreement with experimental data

The peak efficiency for all the three rotational speeds occurs at a velocity ratio lower than the usual 0.70 for radial turbines. The numerical tests performed on the same turbine with different clearance ratios show that the efficiency decreases with the clearance between the rotor blade tip and the casing. This is due to the secondary flow resulting from the high pressure difference between the pressure side and the suction side near the blade tip in one hand and the inactive part of the flow through the section between the blade and the casing. 
The numerical simulation of the turbine under pulsed inlet flow conditions is performed with a constant inlet total temperature and rotational speed. The results show clearly an improved agreement with experiment which indicates the capability of the code and the modeling approach to capture the details of the flow field under pulse conditions. It has been shown that the turbine characteristics depart from those obtained under steady state inlet flow conditions in a hysterisis like shape.

\section{References}

[1] M. Abidat, Design and testing of a highly loaded mixed flow turbine, Ph.D. Thesis, Imperial College, London, 1991

[2] M. Abidat, H. Chen, N.C. Baines, M.R. Firth, Design of a Highly loaded mixed flow turbine, Proc., IMechE, J. Power Energy 206 (1992) 95-107

[3] M. Abidat, M. Hachemi, M. K. Hamidou, N.C. Baines, Prediction of the steady and non-steady flow performance of a highly loaded mixed flow turbine, Proc., IMechE, J. Power Energy 212 (1998) 173-184

[4] C. Arcoumanis, I. Hakeem, R.F. Martinez-Botas, L. Khezzar, N.C. Baines, Performance of a Mixed Flow Turbocharger Turbine under Pulsating Flow Conditions, ASME, Paper 95-GT-210

[5] H. Chen, I. Hakeem, R.F. Martinez-Botas, Modelling of a turbocharger turbine under pulsating inlet conditions, Proc., IMechE, J. Power Energy 210 (1996) 397-408

[6] N. Karamanis, R.F. Martinez-Botas, C.C. Su, Mixed flow turbines: Inlet and exit flow under steady and pulsating conditions, ASME, J. Turbomachinery 123 (2001) 359371

[7] F.S. Bhinder, P.S. Gulati, A method for predicting the performance of centripetal turbines in non-steady flow, IMechE (1978)

[8] V. Gabette, Ph. San Emeterio, Ph. Arques, Influence d'un écoulement pulsé sur les caractéristiques de fonctionnement d'une turbine de suralimentation de moteur thermique, Mécanique Materiaux Electricité $\mathrm{n}^{\circ}$ 394395 octobre/novembre 1982

[9] A. Dale, N. Watson, Vaneless Radial Turbocharger Turbine Performance, IMechE 1986, C110/86

[10] H. Chen, D.E. Winterbone, A method to predict performance of vaneless radial turbines under steady and unsteady flow conditions, IMechE (1990)

[11] A. Hammoud, Q.C. Duan, J. Julien, Étude de la validité de l'hypothèse de quasi-stationnarité appliquée au fonctionnement d'une turbine de suralimentation en régime pulsé, Entropie 174/175 (1993)

[12] P. Bradshaw, T. Cebeci, J.H. Whitelaw, Engineering calculation methods for turbulent flow, Academic Press, London, 1981

[13] S.V. Patankar, D.B. Spalding, A calculation procedure for heat, mass and momentum transfer in three-dimensional parabolic flows, Int. J. Heat Mass Transf. 15 (1972) 1778 1806

[14] F.R. Menter, Two-equation eddy-viscosity turbulence models for engineering applications, AIAA-J. 32 (1994)

[15] C.M. Rhie, W.L.A. Chow, Numerical Study of the Turbulent Flow Past an Isolated Airfoil with Trailing Edge Separation, AIAA J. 21 (1982)

[16] CFX5 Solver Theory, 2004

[17] C.A. Rodgers, Cycle analysis technique for small gas turbines, Technical advances in gas turbine design, Proc. IMechE 183 (1969)

[18] H.E. Rohlik, Analytical determination of radial-inflow turbine design geometry for maximum efficiency, NASA TN D-4384 (1968)

[19] H. Chen, N.C. Baines, M. Abidat, Exit traverse study of mixed-flow turbines with inlet incidence variation, Proc. Inst. Mech. Engrs. 211 (1997) 461-475

[20] D. Palfreyman, R.F. Martinez-Botas, The pulsating flow field in a mixed flow turbocharger turbine: an experimental and computational study, Trans. ASME J. Turbomachinary 127 (2005) 144-155 